\title{
Towards a Sustainable World
}

\author{
H. H. Kleizen \\ IDEGO, Delft University of Technology, The Netherlands
}

\begin{abstract}
The world has a limited potential. Mankind has to balance its activities with those of the Geosphere (atmosphere, hydrosphere and lithosphere) and those of the Biosphere (from whales to archea). This balance leads to the concept of a Sustainable Technological World (STW) encompassing all artifacts (factories, houses, mobile phones) and their needs (air, water, soil, energy) and constraints (emissions). This STW is summarized giving estimates of its main parameters. A Sustainable World is more than the STW. In a Sustainable World people (present and future generations) have equal opportunities to take their share of the STWartifacts. But societies (per continent, country, region, city, etc) have also different starting positions. First a novel method is presented to characterize the structure of the world population, revealing differences and similarities on the same level (country for example) or on different levels (continent and city for example). Secondly the Hofstede 5 cultural dimensions are analyzed and a new culture model is proposed based upon the sequence of 3 of the 5 dimensions. The world population has more than 6 cultures and for 88 countries the culture is given. Evidence is found that the population structure and culture model are linked. This opens a window to connect culture and the limited resources available to mankind.
\end{abstract}

Keywords: culture, population, society, STW, sustainability, technology.

\section{Introduction}

Not everybody likes to possess everything forever. According to Brundtland [1] sustainable development is development that meets the needs of the present without comprising the ability of future generations to meet their needs. One way to interpret this much quoted statement is that there have to be opportunities for those who populate the Earth nowadays and they should increase the opportunities for the generations to come. So indeed the very idea that some 
entity claims all the artefacts on Earth is outrageous. But the question remains: how much is available for mankind and how do we safeguard the distribution of goods and services among the people of the Earth in time?

This paper will not solve this problem. It will contribute to a solution in three ways.

First it treats a Sustainable Technological World (STW), a concept of Kleizen [2,3], encompassing all material, energy, water and air that mankind has maximal available for technology and services. Fair distribution means simply that the amount available is divided by the 6.4 billion people living on Earth nowadays, as estimated in the CIA Factbook [4]. But large societies can create complex products and services, small societies have to keep these goods simple or compete by cooperation. A new model has been published recently by Kleizen $[5,6]$ to break down the world population down in smaller societies (world, continents, countries, provinces, cities, neighbourhoods, streets etc).

How goods are appreciated depends on culture. To quote Hofstede 's favourite statement [7] of Pascal: " There are truths on this side of the Pyrenees that are falsehoods on the other". In his book Hofstede [7] recognizes 5 cultural dimensions. The third new element in this paper is to select only 3 of them giving rise to 6 world cultures as demonstrated by Kleizen [2]. So a new picture is made with fewer pixels but still supporting Pascal's statement.

The paper presents some evidence that the novel culture and structure model are linked [6] allowing one to address the distributional problem: A connection is made between the material dimension (artefact, air, water and energy), the size/complexity dimension and the cultural dimension.

\section{Sustainable Technological World}

The relevant parts of the STW concept as presented in [2,5] are summarized. Humans are part of the living matter on Earth together forming the biosphere. The biosphere is dispersed in the upper region of the Earth called the geosphere. The geosphere contains three subspheres: the atmosphere, hydrosphere and the lithosphere.

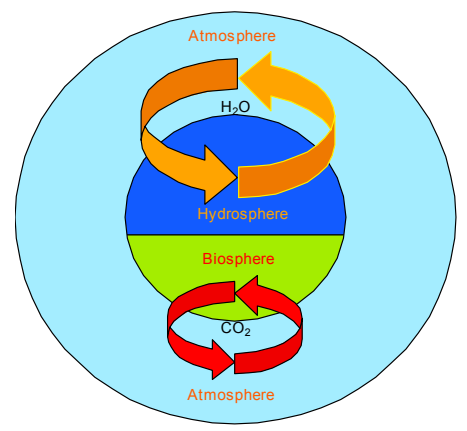

Figure 1: The 2 grant cycles on Earth. 
The geosphere contains three subspheres: the atmosphere, hydrosphere and the lithosphere. Where the atmosphere meets a water surface mass exchange and life occurs: wet soil (the lithosphere) or seas (the hydrosphere). The two great cycles on Earth are depicted in Figure 1.

The greatest cycle is the mass exchange between hydrosphere and atmosphere. The 1.7 billion Gton (Lide and Frederikse [8]) heavy hydrosphere evaporates annually about 540 thousand Gton (Houghton [9], Grübler [10]) water and gets it back as precipitation from the 5.1 million Gton ((Lide and Frederikse [8]) weighing atmosphere. Meanwhile the biosphere, with an estimated mass of 5.7 thousand Gton (Smil [11]), inhales $300 \mathrm{Gton} / \mathrm{yr}$ (Smil [11], Dunn [12]) carbon dioxide from the atmosphere reduces it and sends it back after oxidation. The two cycles are coupled to energy exchange. The H-cycle between atmosphere and hydrosphere involves the vaporisation and condensation of water and the $\mathrm{C}$-cycle between biosphere and atmosphere the carbon fixation in plants and carbon oxidation in plants and animals.

A third cycle involves the STW, the sustainable collection of technological artefacts on Earth. See Figure 2. The mass of the STW and its molar flux to and from the atmosphere is postulated making two assumptions about the position of the STW with respect to hydrosphere and biosphere. Oxygen is selected as the characteristic molecule shuttling between STW and atmosphere and water reduction is chosen to maximise the power associated with oxygen exchange. The major properties of the STW are collected in Table 1.

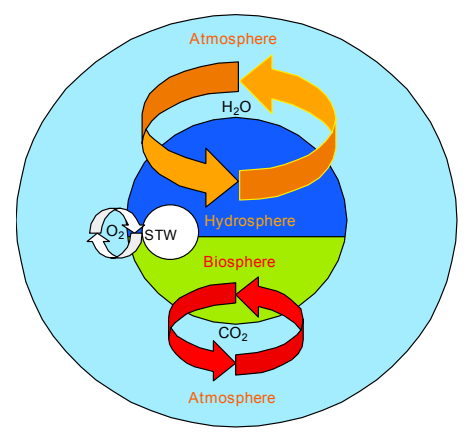

Figure 2: $\quad$ The STW the $3^{\text {rd }}$ cycle.

Table 1: $\quad$ STW properties.

\begin{tabular}{lll}
\hline Basic properties & & \\
\hline Mass STW & 110 & $\mathrm{Gton}$ \\
Power STW & 8800 & $\mathrm{GW}$ \\
Life-span artifacts, average & 25 & $\mathrm{yr}$ \\
\hline Benchmarks & & \\
\hline Annual production of artifacts & 4.4 & $\mathrm{Gton} / \mathrm{yr}$ \\
Specific energy consumption producing artifacts & 64 & $\mathrm{MJ} / \mathrm{kg}$ \\
Specific power consumption STW & 80 & $\mathrm{~mW} / \mathrm{kg}$ \\
\hline Air and water flows & & \\
\hline Air & 375 & $\mathrm{Gton} / \mathrm{yr}$ \\
Water & 100 & $\mathrm{Gton} / \mathrm{yr}$ \\
\hline
\end{tabular}




\section{Structuring societies}

This model has been published in the same form elsewhere [5,6].

The population of a society can be classified using a logarithmic distribution like in filtration. The population is described by $2^{\mathrm{N}}$ with $\mathrm{N}$ an integer and therefore a class width of 2. (In each class the number of people varies from $\mathrm{N} / \sqrt{2}$ up to $\mathrm{N} \sqrt{2}$.) In the CIA World Factbook [4] one counts 236 counties (nations, dependent areas and other entities) permanently populated by 6.446 billion people (July 2005 estimate). In Figure 3 the distribution over the World population over de 236 countries is sketched in terms of $\mathrm{N}$.
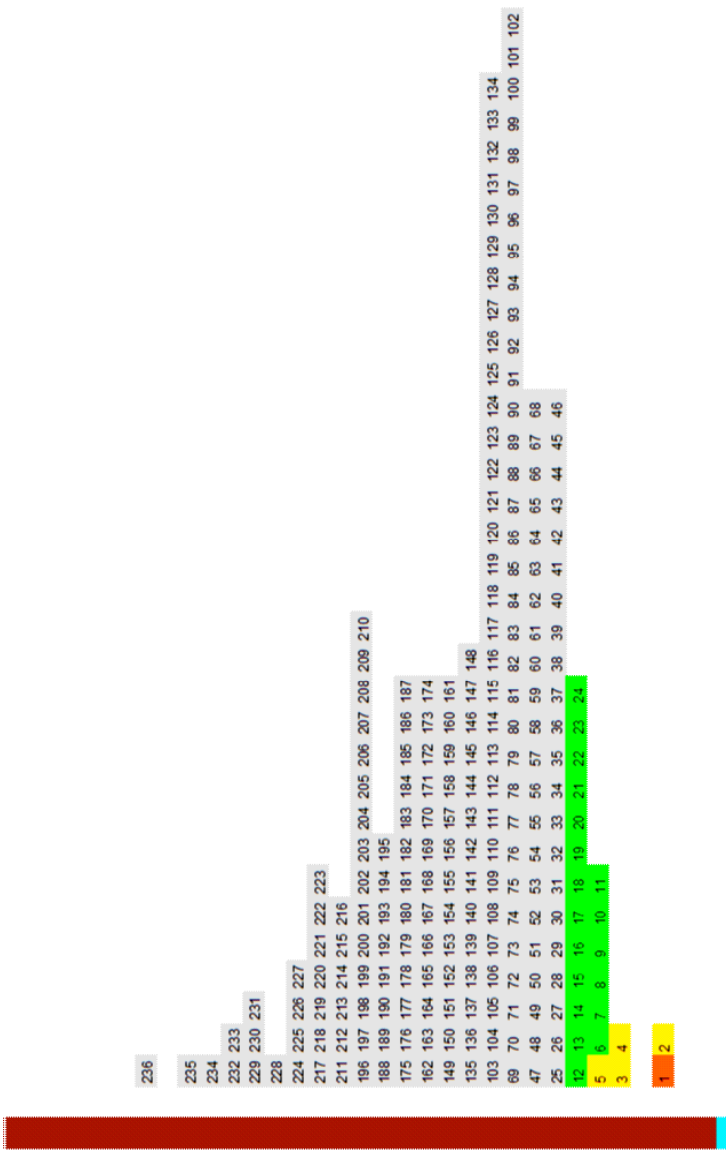

Figure 3: $\quad$ The World population distributed over 236 countries in terms of $\mathrm{N}$.

The World population fells in class $\mathrm{N}=33$. The largest countries China and India are in class $\mathrm{N}=30$ and the smallest one - the Pitcairn Islands - with a population of 46 are in class $\mathrm{N}=6$. 
To describe the World top down a second variable is introduced: the order $\mathrm{m}$ of the distribution. The order $\mathrm{m}$ is equal to difference between the $\mathrm{N}$-value of the society and the one of the largest subsociety. Thus the world has the order 3 (33$30=3)$. Too complete the topdown description three indices hkl are introduced, which satisfy the condition,

$$
2^{N}=h \cdot 2^{N-m}+k \cdot 2^{N-m-1}+l \cdot 2^{N-m-2}
$$

with $1, \mathrm{k}=0,1,2,3$ and $\mathrm{h}=1,2,3, \ldots$ since there is at least 1 largest subsociety. The number of hkl solutions is equal to $4^{\mathrm{m}}$ as can be verified from Table 2. To avoid confusion the k-indices are underlined.

Table 2: $\quad$ The hkl solutions for $\mathrm{m}=0,1$ and 2 .

\begin{tabular}{|c|c|c|c|c|c|c|}
\hline $\begin{array}{r}\mathrm{m}=0 \\
\mathrm{hk} \text { ( }\end{array}$ & $\begin{array}{r}\mathrm{m}=1 \\
\mathrm{hk} 1\end{array}$ & hkl & $\begin{array}{r}\mathrm{m}=2 \\
\mathrm{hk} 1\end{array}$ & hkl & $\mathrm{hkl}$ & $\mathrm{hkl}$ \\
\hline 100 & 200 & \multirow{3}{*}{$\begin{array}{l}120 \\
1 \underline{12} \\
104\end{array}$} & 400 & 320 & 240 & 160 \\
\hline & & & & 312 & $2 \underline{3} 2$ & $1 \underline{5} 2$ \\
\hline & & & & $3 \underline{0} 4$ & 224 & $1 \underline{4} 4$ \\
\hline & & & & & 216 & $1 \underline{3} 6$ \\
\hline & & & & & $2 \underline{0} 8$ & $1 \underline{2} 8$ \\
\hline & & & & & & $1 \underline{110}$ \\
\hline & & & & & & $1 \underline{0} 12$ \\
\hline
\end{tabular}

The world with $\mathrm{N}=33, \mathrm{~m}=3, \mathrm{~h}=2$ (China and India), $\underline{\mathrm{k}}=\underline{0}$ (no country with $\mathrm{N}=29$ ) gets then an 1 -value of 24 as calculated from equation (1).

The model can be applied to all kind of societies, from soccer teams to parliament seats occupied by political parties (Kleizen [2]).

\section{World cultures}

Hofstede [7] in his well-known study recognizes five cultural dimensions: The Power Distance Index (PDI), the Uncertainty Avoidance Index (UAI), the Individualism Index (IDV), the Masculinity Index (MAS) and the Long Term Orientation Index (LTO). A society has its own set of 5 values for these 5 indexes. Hofstede supplies data for 66 countries and ITIM [13] gives elaborated guesses for another 22, so that a list can be made (Kleizen [2]) of 88 countries of the 236 in previous paragraph. (Since LTO was discovered later, some countries are described by 4 dimensions.)

Kleizen [2,6] does make a distinction between the 5 dimensions. Sex came late on an evolutionary time scale and long term orientation is definitely not in Darwinism. So PDI $(=\mathrm{B})$, UAI $(=\mathrm{C})$ and IDV $(=\mathrm{D})$ are considered more basic and applicable also to mammals and more simple living creatures. A second simplification is to look at the sequence of values not at the absolute values themselves. Than there are of course $3 !=6$ sequences: $\mathrm{BCD}, \mathrm{CBD}, \mathrm{CDB}, \mathrm{DCB}$, 
DBC and BDC. In Table 3 the 88 countries are classified by their sequence (= World culture). 83 countries have unique sequences and 5 countries have double sequences because two indexes are the same.

Population averages can be calculated for each index and sequence using the general formula,

$$
V=\sum_{i=1}^{i=j} f_{i} \cdot V_{i}
$$

with $\mathrm{V}$ the population average of a given index of a given sequence, $\mathrm{f}_{\mathrm{i}}$ the population fraction of country $i, V_{i}$ the index of country $i$ and $j$ the number of countries with that sequence. Countries with double sequence participate in both sequences with half of the population.

Table 3: $\quad$ B,C,D, sequence of the 88 countries [2].

\begin{tabular}{|c|c|c|c|c|c|c|}
\hline $\mathrm{nr}$ & $\mathrm{BCD}$ & CBD & CDB & DCB & DBC & $\mathrm{BDC}$ \\
\hline 1 & Albania & Argentina & Austria & Australia & Sweden & Bhutan \\
\hline 2 & Bangladesh & Brazil & Belgium & Canada & & India \\
\hline 3 & Burkino Faso & Bulgaria & Czech Republic & Denmark & & Jamaica \\
\hline 4 & China & Chile & France & Finland & & Singapore \\
\hline 5 & Dominican Republic & Colombia & Hungary & Germany & & Slovakia \\
\hline 6 & Ecuador & Costa Rica & Israel & Ireland & & \\
\hline 7 & Ethiopa & Croatia & Luxembourg & Italy & & \\
\hline 8 & Fiji & Egypt & Malta & Netherlands & & \\
\hline 9 & Ghana & El Salvador & & Norway & & \\
\hline 10 & Hong Kong & Greece & & New Zealand & & \\
\hline 11 & Indonesia & Guatamala & & Switzerland & & \\
\hline 12 & Iraq & Iran & & United States & & \\
\hline 13 & Jordan & Japan & & & & \\
\hline 14 & Kenya & Korea South & & & & \\
\hline 15 & Lebanon & Mexico & & & & \\
\hline 16 & Malawi & Pakistan & & & & \\
\hline 17 & Malaysia & Peru & & & & \\
\hline 18 & Morocco & Poland & & & & \\
\hline 19 & Namibia & Portugal & & & & \\
\hline 20 & Nepal & Russia & & & & \\
\hline 21 & Nigeria & Slovenia & & & & \\
\hline 22 & Panama & Spain & & & & \\
\hline 23 & Philippines & Surinam & & & & \\
\hline 24 & Saudi Arabia & Taiwan & & & & \\
\hline 25 & Sierra Leone & Turkey & & & & \\
\hline 26 & Sri Lanka & Uruguay & & & & \\
\hline 27 & Syria & & & & & \\
\hline 28 & Tanzania & & & & & \\
\hline 29 & Venezuela & & & & & \\
\hline 30 & Vietnam & & & & & \\
\hline 31 & Zambia & & & & & \\
\hline $\mathrm{nr}$ & $\mathrm{BCD}$ & CBD & CDB & DCB & DBC & $\mathrm{BDC}$ \\
\hline 1 & Romania & Romania & & & & \\
\hline 2 & Thailand & Thailand & & & & \\
\hline 3 & & & Estonia & Estonia & & \\
\hline 4 & & & & South Africa & South Africa & \\
\hline 5 & & & & United Kingdom & United Kingdom & \\
\hline
\end{tabular}

The results of the calculations are collected in Table 4. Per index there are 2 maxima, 2 intermediate and 2 minimal values. The differences in each pair are for $\mathrm{C}$ smaller than for $\mathrm{B}$ and $\mathrm{D}$. By a procedure mineralizing deviations it can be shown that the set $\{84,48,36\}$ represent the best fit for maximal, intermediate 
and minimal value for the 3 indexes. In Figure 4 these values are depicted in the $\mathrm{B}, \mathrm{C}$ plane. (In the other planes D,C and D,B the figure the same but the position of the sequences changes with the axes.)

The lines connect the six cultures along the shortest path. Mankind started in Africa and strolling through Table 3 it seems that cultural change is quite slow. All phenomena could be explained by starting with a BCD culture in Africa, going East to find BDC (India) or walking West generating successively CBD, $\mathrm{CDB}, \mathrm{DCB}$ and DBC. Whether or not these cultures were generated before migration or are the result of migration is lost in the mist of times.

Table 4: $\quad$ Population averages of B,C,D-sequences and their sum [2].

\begin{tabular}{llrrrrr}
\hline Sequence & $\begin{array}{l}\text { Nr of } \\
\text { countries }\end{array}$ & $\begin{array}{r}\text { Population } \\
\text { July2005est }\end{array}$ & B=PDI & C = UAI & D = IDV & B+C+D \\
\hline BCD & 32 & 2494209634 & 79.2 & 41.1 & 21.4 & 142 \\
CBD & 27 & 1322629339 & 67.0 & 81.8 & 33.5 & 182 \\
CDB & 8.5 & 107263665 & 56.7 & 83.5 & 68.6 & 209 \\
DCB & 13.5 & 589420094 & 39.5 & 51.6 & 83.0 & 174 \\
DBC & 2 & 61394571 & 39.5 & 39.2 & 77.7 & 156 \\
BDC & 5 & 1095089282 & 77.1 & 39.8 & 47.9 & 165 \\
\hline BCD & all 88 & $\mathbf{5 6 7 0 0 0 6 5 8 3}$ & $\mathbf{7 1 . 0}$ & $\mathbf{5 2 . 2}$ & $\mathbf{3 7 . 3}$ & 160 \\
\hline
\end{tabular}

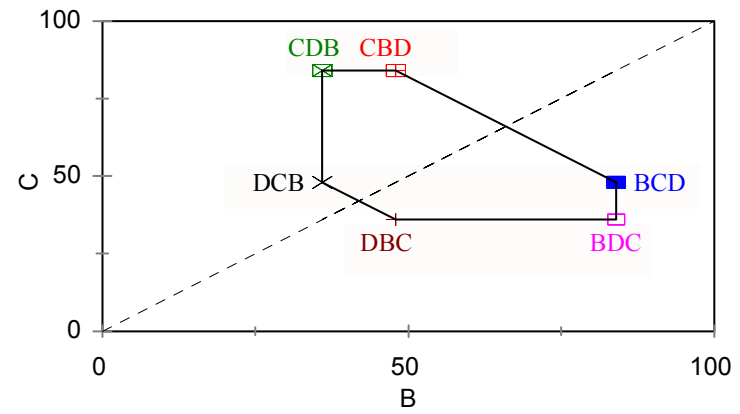

Figure 4: The 6 sequences in the B,C- plane allowing only the values $\{84,48,36\}[2]$.

\section{Linking the 2 models}

The society structure models deals with the relative size of societies. The culture sequence model is based upon the sequence of 3 of the 5 Hofstede dimensions. The individualism index deals with the behavior of individuals within a group and cannot be related to different societies. The uncertainty avoidance index focuses on handling uncertainties and can not possible be related to other known societies. Therefore Kleizen [2] argues the link - if any - should be found in the PDI (=B) index. Hofstede [7] distinguishes 40 key differences (in the family, at 
school, in the work organization) between low and high PDI values. One of them could make the connection. Flat organization pyramids have a low PDI, tall organization pyramids correlate with high PDI. The structure model cannot be flatter than $\mathrm{h} \underline{k} \mathrm{l}=\mathrm{h} \underline{0} 0$. So flatness could bridge both models. The population fraction of the largest subsocieties $r$,

$$
r=\frac{h \cdot 2^{N-m}}{2^{N}}=\frac{h}{2^{m}}
$$

is introduced as a measure of flatness. If $r=1$ the society structure is flat and $\mathrm{B}$ (=PDI) is expected to be low and with decreasing $\mathrm{r}$, B should increase.

First evidence is found in the calculated culture of the European Union up to its $11^{\text {th }}$ lustrum. (No Hofstede data are available on Cyprus, Latvia and Lithuania so the comparison is based upon $98.6 \%$ of the EU-27 population.) From Table 5 it can be learnt that $\mathrm{r}$ and $\mathrm{B}$ behave in the way expected.

Table 5: EU evolution 1952-2007 in terms of $\mathrm{r}, \mathrm{B}$ and sequence $[2,6]$.

\begin{tabular}{ll|r|r|rl}
\hline EU & & Population & $\mathrm{r}$ & $\mathrm{B}=$ PDI & Sequence \\
& & est & & & \\
\hline 1952 & EU-6 & $1.6 \mathrm{E}+08$ & 0.5 & 50.2 & $\mathrm{CDB}$ \\
1973 & EU-9 & $2.6 \mathrm{E}+08$ & 1 & 45.9 & $\mathrm{DCB}$ \\
1986 & EU-12 & $3.3 \mathrm{E}+08$ & 1 & 48.3 & $\mathrm{DCB}$ \\
1995 & EU-15 & $3.7 \mathrm{E}+08$ & 1 & 46.3 & $\mathrm{DCB}$ \\
2004 & EU-25 & $4.6 \mathrm{E}+08$ & 0.5 & 49.2 & $\mathrm{CDB}$ \\
2007 & EU-27 & $4.9 \mathrm{E}+08$ & 0.5 & 51.4 & $\mathrm{CDB}$ \\
\hline
\end{tabular}
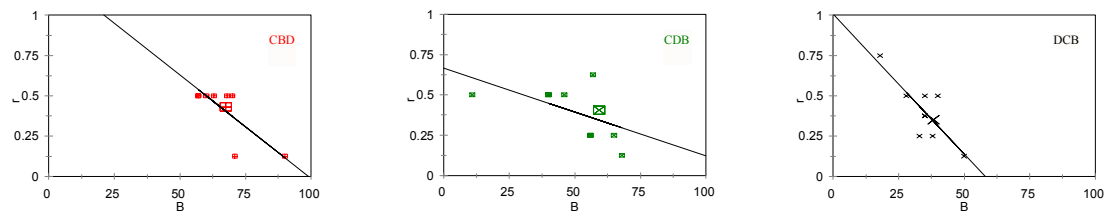

Figure 5: $\quad$ Regression line and population average (larger symbol) for the 3 major sequences of EU-27 countries in terms of their subsocieties (Amts, etc). After $[2,6]$.

In the case of the EU the culture of the subsocieties is known and the culture of the society (the EU) calculated. Looking at countries in terms of Amts Bundesländer, counties, departments, krajs, provinces etc, the cultures of the larger subsocieties are unknown and are assumed the same as the country. In the EU the major sequences are $\mathrm{CBD}, \mathrm{CDB}$ and $\mathrm{DCB}$, see also Table 3. The dependence of $\mathrm{r}$ on $\mathrm{B}$ is depicted fin Figure 5 for these 3 major cultures of EUcountries.

It can be concluded that $\mathrm{B}$ and $\mathrm{r}$ correlate as expected upon the level supranational/national as well as national/regional. 


\section{Discussion}

In this paper 3 models have been shortly presented. The STW is a concept of how large the Technological World might be without disturbing the balance with the Biosphere and Geosphere on planet Earth. The structure model of societies enabling the world population in nested societies (continental societies, supranational entities like Asean, EU and Nafta, countries, provinces, cities) but also in term of multinationals, national companies, LE's and SME's and nonprofit organizations. The culture model as presented divides the World in 6 cultures. It is still incomplete as only data on 88 of 236 countries are known, but in these 88 countries $88 \%$ of the World population lives, so the lack of data is not a major concern.

Together the 3 models have the potential to become basic instruments in a toolkit to increase the rate of sustainable change and avoid durable excursions in the jungle left and right of this road to be paved.

An example to illustrate this point: China (BCD), India (BDC) and the USA (DCB) have different cultures. The EU may stick to the fourth culture CDB, but if it wants to beat the competition, it should first research why CDB is so innovative. And if isn't, the EU should reformulate it research frameworks and perhaps give credit to its major cultures $\mathrm{CBD}, \mathrm{CDB}$ and $\mathrm{DCB}$ to take the driving seat.

The 3 models are models and could become stronger if they could be unified. The future will learn from the past [14].

\section{Conclusion}

The STW, structure and culture model are valuable instruments in the durable sustainable development theories of Life on Earth.

\section{References}

[1] Brundtland G., Our Common Future, The World Commission on Environment and Development, Oxford University Press: Oxford, 1987.

[2] Kleizen H.H., Towards a Sustainable Technological World, Thesis Delft University of Technology, in press, 2006.

[3] Kleizen H.H., Air and Water Filtration in a Sustainable Technological World, In: Höflinger W. (ed). Chemical industry and Environment V. Vienna (Austria), 2006: 785-792.

[4] CIA - The World Factbook, www.cia.gov/cia/publications/factbook/geos/ in.html

[5] Kleizen H.H., Structuring the World and Sustainable Air Sharing, In: Mander U, Brebbia CA and Tiezzi E (ed) The Sustainable City IV, Proceedings $4^{\text {th }}$ Int Conference Sustainability City 2006, Wit Press, Tallinn (Estonia), 2006: 303-311. 
[6] Kleizen H.H., A Novel Method to structure the World in Population Entities and Application to European Countries and Regions, $46^{\text {th }}$ ERSA Conference, Aug 30- Sep 3, Volos (Greece) 2006.

[7] Hofstede G., Culture's Consequences, Comparing Values, Behaviors, Institutions and Organizations Across Nations, Sage Publications, California, 2001.

[8] Lide, D.R. \& Frederikse, H.P.R., (eds), Handbook of Chemistry and Physics, CRC Press: Boca Raton, Ann Archor, London \& Tokyo, pp. 144 \& 14-5, 1993.

[9] Houghton J., Global Warming: The complete Briefing, Cambridge University Press: Cambridge, 1997.

[10] Grübler, A., Technology and Global Change, Cambridge University Press: Cambridge, 1998.

[11] Smil, V., Elementaire Kringlopen- Wisselwerking tussen biosfeer en beschaving, Natuur \& Techniek: Amsterdam, 1999. Dutch translation of: Smil., V., Cycles of Life, Civilization and the Biosphere, The Scientific American Library: New York, 1997.

[12] Dunn, S., Decarbonizing the Energy Economy, in: State of the World 2001, A Worldwatch Institute Report on Progress towards a Sustainable Society, W.W.Norton \& Co: New York, Chapter 5, pp. 83-102, 2001.

[13] ITIM, 5-D Pocket Guide, Brochure, 2001.

[14] Kleizen H.H., S Particle Systems: Predicting Number of the Chemical Elements and Shape and Function of Crystals and Enabling Molecules, Unpublished Work, 1970-1982. 